\title{
Neuroanatomical differences between first-episode psychosis patients with and without neurocognitive deficit: a 3-year longitudinal study
}

\section{Rosa Ayesa-Arriola ${ }^{1,2+}$, Roberto Roiz-Santiáñez ${ }^{1,2+}{ }^{*}$, Rocío Pérez-Iglesias $^{1,2,3}$, Adele Ferro $^{4}$, Jesús Sainz ${ }^{5}$ and Benedicto Crespo-Facorro ${ }^{1,2}$}

1 Department of Psychiatry, School of Medicine, University of Cantabria, University Hospital Marqués de Valdecilla, IFIMAV, Santander, Spain

${ }^{2}$ CIBERSAM, Centro Investigación Biomédica en Red Salud Mental, Madrid, Spain

${ }^{3}$ Psychosis Studies Department, Institute of Psychiatry, London, UK

${ }^{4}$ Department of Experimental Clinical Medicine, Inter-University Center for Behavioural Neurosciences (ICBN), University of Udine, Udine, Italy

${ }^{5}$ CSIC, Spanish National Research Council, Institute of Biomedicine and Biotechnology of Cantabria, University of Cantabria, Santander, Spain

\section{Edited by:}

Stefan Borgwardt, University of

Basel, Switzerland

Reviewed by:

Joaquim Radua, King's College London, UK

Renata Smieskova, University

Psychiatry Clinics, Switzerland

\section{*Correspondence:}

Roberto Roiz-Santiáñez, Unidad Investigación Psiquiatría, Hospital Universitario Marqués de Valdecilla., Avda. Valdecilla s/n, 39008 Santander, Spain

e-mail: rroiz@humv.es

${ }^{\dagger}$ Rosa Ayesa-Arriola and Roberto Roiz-Santiáñez have contributed equally to this work and should be considered co-first authors.

\begin{abstract}
Background: The course of cognitive function in first-episode psychosis (FEP) patients suggests that some individuals are normal or near normal whereas some cases present a marked decline. The goal of the present longitudinal study was to identify neuroanatomical differences between deficit and non-deficit patients.
\end{abstract}

Methods: Fifty nine FEP patients with neuroimage and neurocognitive information were studied at baseline and 3 year after illness onset. A global cognitive function score was used to classify deficit and non-deficit patients at baseline. Analysis of covariances and repeated-measures analysis were performed to evaluate differences in brain volumes. Age, premorbid $I Q$, and intracranial volume were used as covariates. We examined only volumes of whole brain, whole brain gray and white matter, cortical CSF and lateral ventricles, lobular volumes of gray and white matter, and subcortical (caudate nucleus and thalamus) regions.

Results: At illness onset $50.8 \%$ of patients presented global cognitive deficit. There were no significant differences between neuropsychological subgroups in any of the brain regions studied at baseline [all $F(1,54) \leq 3.42$; all $p \geq 0.07$ ] and follow-up [all $F(1,54) \leq 3.43$; all $p \geq 0.07$ ] time points. There was a significant time by group interaction for the parietal tissue volume $[F(1,54)=4.97, p=0.030]$ and the total gray matter volume $[F(1,54)=4.31$, $p=0.042]$, with the deficit group showing a greater volume decrease.

Conclusion: Our results did not confirm the presence of significant morphometric differences in the brain regions evaluated between cognitively impaired and cognitively preserved schizophrenia patients at the early stages of the illness. However, there were significant time by group interactions for the parietal tissue volume and the total gray matter volume during the 3-year follow-up period, which might indicate that cognitive deficit in schizophrenia would be associated with progressive brain volume loss.

Keywords: first-episode psychosis, neuroanatomical, neurocognition, schizophrenia, cognitive deficit

\section{INTRODUCTION}

Cognitive deficits are core features of schizophrenia that are already evident at early phases of the illness $(1,2)$, with more than $80 \%$ of patients showing deficits in one or more domains of cognitive function (3). There are, however, noticeable differences among patients, with a subgroup showing severe and debilitating cognitive dysfunctions, typical of Kraepelin's description of dementia praecox (4), and other subgroup considered to be "neuropsychologically normal" (5). These distinguishable subgroups probably lie at different levels of severity on a continuum of causes or of different factors that might be influencing outcome (6).

Cognitive functioning has been associated with measures of brain structures both in schizophrenia patients and healthy subjects (7). It is now well established that schizophrenia is also associated with structural brain abnormalities $(8,9)$. Although some longitudinal magnetic resonance imaging (MRI) studies have reported a progressive brain tissue loss during the early years after the first psychotic episode of schizophrenia compared to healthy subjects (10-12), others have failed to reveal such progressive brain volume loss (13-18). Nevertheless, only few studies have examined those brain abnormalities that characterize the disorder in cognitive subgroups and, to the best of our knowledge, there are no previous studies that have examined progressive brain changes associated with cognitive deficit in schizophrenia.

The aim of this study was to identify neuroanatomical differences that possibly underlie neurocognitive function deficit in 
first-episode psychosis (FEP) patients followed up for 3-years. Previous studies have associated white matter abnormalities with cognitive deficit (19,20). Perez-Iglesias and colleagues (19), using diffusion tensor imaging, showed that deficits in executive and motor functioning in patients with FEP were associated with reductions in white matter integrity, and Wexler et al. (20) found that neuropsychologically impaired patients had significantly smaller white matter volumes in several regions. On the basis of these studies, we hypothesized that patients with cognitive deficit would present a white matter volume diminution.

\section{MATERIALS AND METHODS \\ STUDY DESIGN AND SETTING}

Data for the present investigation were obtained from a large epidemiological and 3-year longitudinal intervention program of FEP (PAFIP) conducted at the outpatient clinic and the inpatient unit at the University Hospital Marques de Valdecilla, Santander, Spain. It conformed to international standards for research ethics and was approved by the local institutional review board. Informed consent of the participants was obtained after the nature of the procedures had been fully explained. The referrals to the PAFIP came from the inpatient unit and emergency room at the University Hospital Marques de Valdecilla, community mental health services and other community health care workers in Cantabria. A more detailed description of our program has been previously reported $(21,22)$.

\section{SUBJECTS}

All the patients included in PAFIP from February 2001 to December 2007 were invited to participate in this study. Patients referred to the program were selected if they met the following criteria: (1) 15-60 years; (2) living in the catchment area; (3) experiencing their first-episode of psychosis; (4) no prior treatment with antipsychotic medication or, if previously treated, a total life time of adequate antipsychotic treatment of less than 6 weeks; (5) DSMIV criteria for brief psychotic disorder, schizophreniform disorder, schizophrenia, or schizoaffective disorder. Patients were excluded for any of the following reasons: (1) meeting DSM-IV criteria for drug dependence, (2) meeting DSM-IV criteria for mental retardation, (3) having a history of neurological disease or head injury. Our operational definition for a "first-episode of psychosis" included individuals with a non-affective psychosis (meeting the inclusion criteria defined above) who have not received previously antipsychotic treatment regardless the duration of psychosis. Individuals who entered the study received extensive clinical and psychopathological assessments and were examined by MRI scan. Only those patients who had a baseline neuropsychological assessment and completed both baseline and 3-year follow-up MRI scans were included in this study. Thus, 59 patients with a schizophrenia-spectrum disorder (schizophrenia $N=37,62.7 \%$; schizophreniform disorder, $N=15,25.4 \%$; schizoaffective disorder, $N=2$, 3.4\%; brief psychotic disorder, $N=2,3.4 \%$; not otherwise specified psychosis, $N=3,5.1 \%$ ) were included in the study.

The diagnoses were confirmed using the Structured Clinical Interview for DSM-IV (SCID-I) (23) carried out by an experienced psychiatrist 6 months after the baseline visit.
A group of healthy subjects $(N=43)$ who had no current or past history of psychiatric illness, including substance dependence, neurological or general medical disorders, as determined by using an abbreviated version of the Comprehensive Assessment of Symptoms and History (CASH) (24), was recruited from the local area. The controls underwent the same cognitive battery as the patients. After a detailed description of the study, each healthy subject gave their written informed consent to participate, in accordance with the local ethics committee (25).

There were no significant differences in a variety of variables (e.g., age at baseline, age of onset, academic level, alcohol, cannabis, or tobacco consumption, duration of untreated psychosis (DUP), duration of untreated illness (DUI), or symptomatology factors) between patients who were and those who were not included in the final analysis (all $p>0.236)$.

\section{CLINICAL ASSESSMENT}

Clinical symptoms were assessed by using the Brief Psychiatric Rating Scale total (BPRS) (26), the Scale for the Assessment of Negative Symptoms (SANS) (27), and the Scale for the Assessment of Positive Symptoms (SAPS) (28). We also divided psychopathology into three dimensions of symptoms: positive (scores for hallucinations and delusions), disorganized (scores for formal thought disorder, bizarre behavior, and inappropriate affect), and negative (scores for alogia, affective flattening, apathy, and anhedonia) (29).

\section{PREMORBID AND SOCIODEMOGRAPHIC VARIABLES}

Premorbid and sociodemographic information was recorded from patients, relatives, and medical records. Age of onset of psychosis was defined as the age when the emergence of the first continuous (present most of the time) psychotic symptom occurred. DUI was defined as the time from the first unspecific symptoms related to psychosis (for such a symptom to be considered, there should be no return to previous stable level of functioning) to initiation of adequate antipsychotic drug treatment. DUP was defined as the time from the first continuous (present most of the time) psychotic symptom to initiation of adequate antipsychotic drug treatment. Information about alcohol, cannabis, and tobacco consume were converted into binary variables coding for either the presence or absence of use.

\section{MEDICATION ASSESSMENT}

The amount and type of medication being prescribed during the 3 -year follow-up period was thoroughly recorded. Patients were randomized as part of an intervention program out of the scope of the present study. After written informed consent was obtained, patients were randomly assigned to Haloperidol $(N=8)$, Olanzapine $(N=12)$, Risperidone $(N=12)$, Quetiapine $(N=8)$, Ziprasidone $(N=10)$, and Aripiprazole $(N=9)$. At 3-year followup patients were on: Haloperidol $(N=3)$, Olanzapine $(N=8)$, Risperidone $(N=12)$, Quetiapine $(N=5)$ Ziprasidone $(N=4)$, Aripiprazole $(N=8)$, Amisulpride $(N=1)$, Clozapine $(N=2)$, and Risperidone depot $(N=4)$. Eight patients withdrew from the medication, 27 patients switched their medication during followup period, and 2 were taking more than one antipsychotic at the time of follow-up MRI. No reliable information on medication intake was available for four patients. Additional information about concomitant medications is available under request. 


\section{NEUROPSYCHOLOGICAL ASSESSMENT}

For the present study, baseline neuropsychological assessment was considered in both groups, patients, and normal control subjects. Baseline patients' assessment was carried out when clinical status permitted in order to maximize cooperation, and occurred at a mean of 10.5 weeks after intake followed by assessment after 3 years. They were never assessed during a period of clinical exacerbation. A detailed description has been reported elsewhere (1).

For the analysis in this study a subset of measures was selected to assess eight major cognitive domains: (1) for measuring verbal memory we used the Rey Auditory Verbal Learning Test [RAVLT (30)], delayed recall; (2) for measuring visual memory we used Rey Complex Figure [RCF (31)], delayed reproduction; (3) for measuring executive functions we used Trail Making Test [TMT (32)], time to complete TMT-B; (4) for measuring working memory we used the Backward Digits scale [WAIS III (33)], total subscore; (5) for measuring speed of processing we used WAIS III subtest Digit Symbol, standard total score; (6) for motor dexterity we used Grooved Pegboard Handedness (34), time to complete with dominant hand; (7) for measuring attention we used Continuous Performance Test [CPT (35)], total number of correct responses; (8) The WAIS III subtest of Vocabulary was used as measure of premorbid IQ (34), standard total score.

In order to calculate a measure of Global Cognitive Functioning (GCF), raw cognitive scores were reversed when appropriate before standardization so they all have the same direction (the higher, the better). According to previous methodology (36), the GCF was calculated as $T$-scores $($ mean $=50, S D=10)$ with raw scores of the healthy comparison sample. $T$-scores were converted to deficit scores that reflect presence and severity of cognitive deficit. Deficit scores on all tests were then averaged to create the GCF, which according to Keefe and colleagues deficit criterion (37), was dichotomized into two patients' subgroups: "deficit" (GCF $<1$ ) and "non-deficit" (GCF $\geq 1$ ) [see Ref. (6) for details].

\section{MRI DATA ACOUISITION}

A multimodal MRI protocol [T1, T2, and proton density (PD) sequences] was acquired at the University Hospital Marques de Valdecilla, Santander, Spain, using a 1.5-T General Electric SIGNA System (GE Medical Systems, Milwaukee, WI, USA). This multimodal approach was designed to optimize discrimination between gray matter, white matter, and cerebrospinal fluid. The T1-weighted images, using a spoiled grass (SPGR) sequence, were acquired in the coronal plane with the following parameters: echo time $(\mathrm{TE})=5 \mathrm{~ms}$, repetition time $(\mathrm{TR})=24 \mathrm{~ms}$, number of excitations $(\mathrm{NEX})=2$, rotation angle $=45^{\circ}$, field of view $(\mathrm{FOV})=26 \mathrm{~cm} \times 19.5 \mathrm{~cm}$, slice thickness $=1.5 \mathrm{~mm}$, and a matrix of $256 \times 192$. The PD and transverse relaxation time (T2)-weighted images were obtained with the following parameters: $3.0 \mathrm{~mm}$ thick coronal slices, $\mathrm{TR}=3000 \mathrm{~ms}, \mathrm{TE}=36 \mathrm{~ms}$ (for PD) and $96 \mathrm{~ms}$ (for T2), $\mathrm{NEX}=1$, $\mathrm{FOV}=26 \mathrm{~cm} \times 26 \mathrm{~cm}$, matrix $=256 \times 192$. The in-plane resolution was $1.016 \mathrm{~mm} \times 1.016 \mathrm{~mm}$. MRIs of patients and controls were evenly acquired during follow-up time.

\section{IMAGE PROCESSING}

Processing of the images after acquisition was done by using a family of software programs called BRAINS2 $(38,39)$. The T1-weighted images were spatially normalized and resampled to $1.0-\mathrm{mm}^{3}$ voxels so that the anterior-posterior axis of the brain was realigned parallel to the anterior commissure/posterior commissure line and the interhemispheric fissure aligned on the other two axes. The T2- and PD-weighted images were then aligned to the spatially normalized T1-weighted image. These images were then subjected to a linear transformation into standardized stereotaxic Talairach atlas space to generate automated measurements of frontal, temporal, parietal, and occipital lobes and also the cerebellum and subcortical regions (39). To further classify tissue volumes into gray matter, white matter, and CSF, we used a discriminant analysis method of tissue segmentation based on automated training class selection that utilized data from the T1-weighted, T2-weighted, and PD sequences (40). The discriminant analysis method permits to identify the range of voxel intensity values that characterize GM, WM, and CSF. An 8 bit number is assigned to each voxel indicating its partial volume tissue content (10-70 for CSF, 70-190 for GM, and 190-250 for WM). In this study we examined the volumes of whole brain (WB), whole brain gray matter (WBGM), whole brain white matter (WBWM), cortical CSF (CCSF), and lateral ventricles (LV), gray and white matter volumes of cortical (occipital, parietal, temporal, and frontal lobes) and subcortical (caudate nucleus and thalamus) regions volume. Caudate and thalamus were delineated using a reliable and validated semiautomated artificial neural network (41). The procedure for measuring the volume of caudate and thalamus are explained in detail in previous studies $(42,43)$.

\section{STATISTICAL ANALYSIS}

The Statistical Package for Social Science, version 19.0 (SPSS Inc., Chicago, IL, USA), was used for statistical analyses. Significance was determined at the 0.05 level.

To examine brain volumetric differences between neurocognitive subgroups (no deficit vs. deficit) at baseline and 3-year follow-up, 1-way ANCOVA was performed. In each general linear model, the dependent measures were MRI volumes and the independent measure was group (no deficit vs. deficit). To test the hypothesis that the two groups would result in different progressive brain volume changes, repeated-measures analysis of covariance (repeated-measures ANCOVA) was performed for each ROI variable. The between-subject factor was group (no deficit vs. deficit) and the within subject factor was time (baseline and 3 year). Effects of time by group (interaction effect) were examined. Age, ICV, and premorbid IQ were included as covariates. There were no differences between groups related to age and ICV. However, there was a wide age range in our sample and the use of these two variables has been suggested in brain volume studies (44). The sample size $(n=59)$ provided sufficient power $(>80 \%)$ to detect large effect sizes $\left(d_{\text {Cohen }}>0.8\right)$ but was underpowered $(45 \%)$ to detect weak or modest effects $\left(d_{\text {Cohen }}<0.5\right)$.

Pearson correlation coefficients with age, ICV, and IQ as covariates were used to investigate possible statistical relationships between brain volume and GCF. 
A prior directional hypothesis had been made for the brain measure analyses, thereby lessening the need for Bonferroni corrections. The analyses examining the relationships between brain measures and GCF were performed without prespecified hypotheses, and therefore Bonferroni adjustments were applied.

\section{RESULTS}

Demographic and clinical data are shown in Table 1. Neuropsychological baseline assessment showed that of the 59 patients included in the study, 30 (50.8\%) presented general neurocognitive deficit. There were no statistically significant differences in relevant demographic and clinical characteristics between patients with neurocognitive deficit $(N=30)$ and patients without it $(N=29)$ at baseline (Table 1). However, the general neurocognitive deficit group showed a significant higher BPRS total score and greater severity of positive (SAPS total and positive dimension) and disorganized (scores for formal thought disorder, bizarre behavior, and inappropriate affect) symptoms at follow-up.

Neuropsychological data is presented in Table 2. The general neurocognitive deficit group had worse premorbid IQ, and showed consistently greater deficits all over cognitive domains. Worse executive function, poor motor dexterity, and particularly attentional deficits marked the more severely deficit patients.
Brain volumes at baseline in FEP subjects are presented in Table 3. There were no significant differences between neuropsychological subgroups in any of the brain regions studied at baseline [all $F(1,54) \leq 3.42$; all $p \geq 0.070$ ] and follow-up [all $F(1$, $54) \leq 3.43$; all $p \geq 0.07$ ] time points (Table 3 ). Patients with cognitive deficit showed overall lower gray and white matter volumes but these differences did not reach statistical significance.

There was a significant time by group interaction for the parietal tissue volume $[F(1,54)=4.97, p=0.030]$, with the general

Table 2 | Comparison of neurocognitive groups on neuropsychological variables (Student's $t$-distribution with 58 degrees of freedom).

\begin{tabular}{llll}
\hline Characteristics & $\begin{array}{l}\text { Non-deficit } \\
(\boldsymbol{N = 2 9 )}\end{array}$ & $\begin{array}{l}\text { Deficit } \\
(\boldsymbol{N}=\mathbf{3 0})\end{array}$ & Statistics \\
\hline Premorbid IO & $-0.08(1.13)$ & $-1.03(1.19)$ & $t=3.07, p=0.003$ \\
Attention & $-0.39(1.5)$ & $-4.41(5.31)$ & $t=3.98, p<0.001$ \\
Verbal memory & $-0.73(1.08)$ & $-1.31(1.08)$ & $t=2.04, p=0.046$ \\
Visual memory & $-0.47(1.1)$ & $-1.16(1.09)$ & $t=2.41, p=0.019$ \\
Working memory & $-0.23(0.51)$ & $-0.84(0.75)$ & $t=3.66, p=0.001$ \\
Executive function & $-0.21(0.74)$ & $-2.51(2.56)$ & $t=4.72, p=0.001$ \\
Processing speed & $-1.02(1.15)$ & $-2.02(0.89)$ & $t=3.75, p=0.001$
\end{tabular}

Table 1 | Sociodemographic and clinical characteristics of the two neurocognitive groups of patients.

\begin{tabular}{|c|c|c|c|}
\hline Characteristics & Non-deficit $(N=29)$ & Deficit $(N=30)$ & Statistics \\
\hline Age at initial MRI, mean (SD), years & $28.50(6.93)$ & $32.12(9.97)$ & $F(1,57)=2.59, p=0.113$ \\
\hline $\mathrm{ICV}$, mean (SD) & $1367.41(128.78)$ & $1343.19(120.18)$ & $F(1,57)=0.56, p=0.458$ \\
\hline Time between scans, mean (SD), (range) days & 1117.96 (39.58) & $1120.63(56.34)$ & $F(1,57)=0.04, p=0.835$ \\
\hline Right-handed, $N(\%)$ & $26(89.7)$ & $25(83.3)$ & $\chi^{2}(1)=0.50, p=0.478$ \\
\hline Alcohol users, $N(\%)$ & $17(58.6)$ & $19(63.3)$ & $\chi^{2}(1)=1.38, p=0.711$ \\
\hline Cannabis users, $N(\%)$ & $15(51.7)$ & $11(36.7)$ & $\chi^{2}(1)=1.35, p=0.244$ \\
\hline Tobacco users, $N(\%)$ & $17(58.6)$ & $16(53.3)$ & $\chi^{2}(1)=0.17, p=0.683$ \\
\hline Age at onset, mean (SD), years & $27.61(6.28)$ & $30.59(9.79)$ & $F(1,57)=1.91, p=0.172$ \\
\hline DUP mean, (SD), (median), months & $10.74(19.39)$ & $18.35(21.15)$ & $F(1,57)=2.07, p=0.155$ \\
\hline SAPS at follow up, mean (SD) & $0.57(1.40)$ & $2.86(4.62)$ & $F(1,55)=6.30, p=0.015$ \\
\hline BPRS at intake, mean (SD) & $62.00(11.67)$ & $63.50(13.68)$ & $F(1,57)=0.21, p=0.653$ \\
\hline BPRS at follow-up, mean (SD) & $27.14(4.33)$ & $32.93(14.17)$ & $F(1,55)=4.28, p=0.043$ \\
\hline \multicolumn{4}{|c|}{ SYMPTOM DIMENSIONS TOTAL SCORES AT BASELINE } \\
\hline Negative (mean) (SD) & $4.75(4.69)$ & $5.40(4.90)$ & $F(1,57)=0.26, p=0.610$ \\
\hline Disorganized (mean) (SD) & $6.07(3.43)$ & $6.10(3.35)$ & $F(1,57)<0.01, p=0.972$ \\
\hline Psychotic (mean) (SD) & $7.37(2.38)$ & $7.57(2.31)$ & $F(1,57)=0.09, p=0.760$ \\
\hline \multicolumn{4}{|c|}{ SYMPTOM DIMENSIONS TOTAL SCORES AT FOLLOW UP } \\
\hline Negative (mean) (SD) & $1.54(2.33)$ & $2.90(4.25)$ & $F(1,55)=2.23, p=0.141$ \\
\hline Disorganized (mean) (SD) & $0.25(0.84)$ & $1.45(2.99)$ & $F(1,55)=4.16, p=0.046$ \\
\hline
\end{tabular}

BPRS, brief psychiatric rating scale; DUP, duration of untreated psychosis; DUI, duration of untreated illness; ICV, intracranial volume; SANS, scale for the assessment of negative symptoms; SAPS, scale for the assessment of positive symptoms; $S D$, standard deviation. Bold values were statistically significant ( $p<0.05)$. 


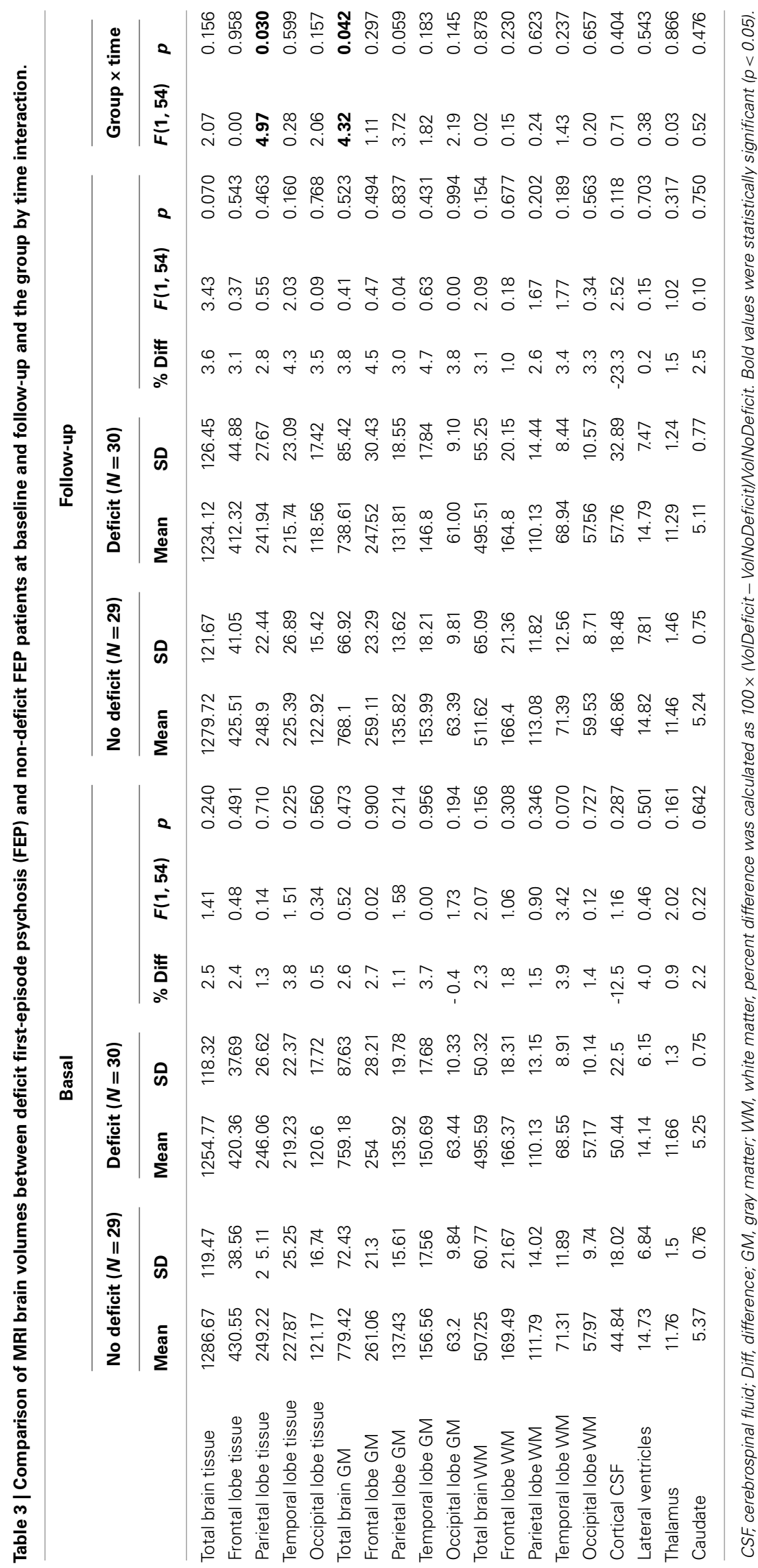




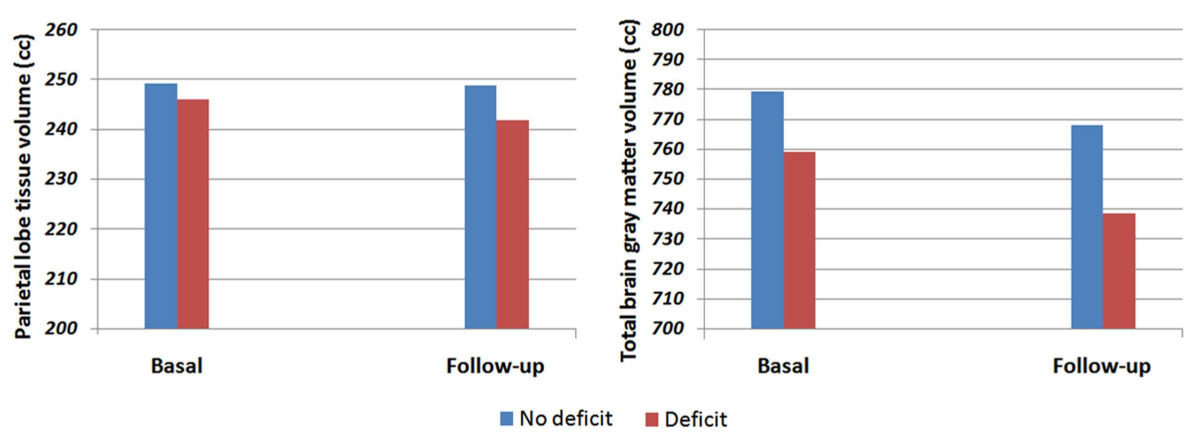

FIGURE 1 |Total gray matter and parietal tissue volume in deficit and non-deficit first-episode psychosis patients.

neurocognitive deficit group showing a greater volume decrease $(1.67 \%)$ than the non-deficit group $(0.13 \%)$. Similarly, there was also a significant time by group interaction for the total gray matter volume $[F(1,54)=4.31, p=0.042]$, showing a greater reduction in the general neurocognitive deficit group $(2.71 \%)$ than in the non-deficit group (1.45\%) (see Figure 1). Interestingly, when the analyses were controlled by possible confounding variables (sex, DUP, tobacco, cannabis, and alcohol consumption) only the parietal lobe tissue showed a significant group by time interaction.

No significant correlations between brain volume at baseline and GCF were found. At follow-up period, there were significant negative correlations between GCF and parietal tissue lobe $(r=-0.29, p=0.031)$ and temporal lobe gray matter $(r=-0.27$; $p=0.049)$. However, these correlations were weak and did not remain significant after correcting for multiple testing (Bonferroni correction).

\section{DISCUSSION}

In the present study, a GCF index was calculated to identify schizophrenia patients who had general neurocognitive deficit at baseline (6). Contrary to our expectations, there were no brain volume differences between the cognitively impaired and cognitively preserved groups at any of the time-point studied. However, there were significant time by group interactions for the parietal tissue volume and the total gray matter volume, with the general neurocognitive deficit group showing a greater reduction in both regions during the 3-year follow-up interval. This is, to the best of our knowledge, the first study to examine progressive brain changes in schizophrenic cognitive deficit.

Neuropsychological assessment carried out at baseline indicated that $50.8 \%$ of the patients included in the study presented general neurocognitive deficit. These results are in full agreement with previous studies in FEP patients (2).

Only two previous cross-sectional studies $(20,45)$ have examined brain volume differences between cognitive subgroups in schizophrenia and their results have been inconclusive. Supporting our results, Ortiz-Gil and colleagues (45) did not find differences in lateral ventricular volume or WB volume between cognitively intact and cognitively deficit schizophrenia patients. Using Voxelbased morphometry, they also failed to detect significant difference in volumes of gray and white matter between those groups. However, Wexler et al. (20), using VBM to compare neuropsychology near normal and neuropsychology impaired subgroups, found that these groups differed significantly from each other in white matter volumes of the sensorimotor and parietal-occipital regions, with the neuropsychology impaired group showing smaller volumes in these brain regions. Nonetheless, it is of note that this VBM study did not adopt any statistical procedures to control for multiple comparisons. It is important to take into account that mean duration of illness among patients was above 18 years in both studies, while our patients had a shorter duration of illness (non-deficit: 28.32 months, deficit: 30.45 months).

Only cross-sectional studies have addressed the relationship between cognitive deficit and brain structure in schizophrenia. However, it has been suggested that this relationship may not be adequately assessed in a cross-sectional study (45). We found significant time by group interactions for the parietal tissue volume and the total gray matter volume, with the general neurocognitive deficit group showing a greater reduction in both regions (parietal tissue volume and the total gray matter volume) during the 3-year follow-up interval. In a recent study (13) we found that brain tissue volumes decrease in patients at early years after the first episode was similar to that found in healthy controls. Although several longitudinal studies in schizophrenia have described a greater degree of brain tissue volumes decrease in the early stage of the illness (10-12), others have failed to confirm these findings (13-18). For a review see Olabi et al. (46). Taken this together, we might speculate that the progressive brain volume loss found in schizophrenia might be associated with this general cognitive deficit patients' subgroup.

\section{LIMITATIONS}

A uniform follow-up interval using the same MRI scanner and protocol, and a thorough clinical investigation during the followup period add strength to the conclusions drawn from this study. However, several limitations should be taken into account when interpreting the results of the current study. First, the diagnostic heterogeneity of the sample might bias our findings. Second, and given the fact that schizophrenia is a life-long disease, a follow-up period of 3 years may be too short to demonstrate other subtle changes. Third, analyses taking into account if neurocognitive function maintained, declined, or improved during follow-up could not be conducted because of the small sample size in our study. Fourth, a major confounding factor could be the intake 
of antipsychotic medication (47). Some studies have showed a relationship between antipsychotic medication use and longitudinal brain volume change in schizophrenia $(10,48)$, although others have failed to clearly demonstrate an influence of antipsychotic medication on brain volume change (49-51). Some patients withdrew from their medication, and most of them switched medication during the 3-year follow-up period, which makes the investigation of the effects of different types of antipsychotics an unfeasible study. Fifth, this study only measured a number of structures, and finally, brain volume changes in schizophrenia are subtle, so the sample size might be considered small to make any definitive assertions. While our data provided sufficient power to detect large effects, the detection of weak effects requires large study populations.

\section{CONCLUSION}

In conclusion, our results, based on a representative sample of firstepisode schizophrenia-spectrum patients, do not confirm the presence of significant morphometric differences between cognitively impaired and cognitively preserved schizophrenia patients at the

\section{REFERENCES}

1. Gonzalez-Blanch C, CrespoFacorro B, Alvarez-Jimenez $\mathrm{M}$, Rodriguez-Sanchez JM, PelayoTeran JM, Perez-Iglesias R, et al. Cognitive dimensions in firstepisode schizophrenia spectrum disorders. J Psychiatr Res (2007) 41(11):968-77. doi:10.1016/j. jpsychires.2006.08.009

2. Bilder RM, Goldman RS, Robinson D, Reiter G, Bell L, Bates JA, et al. Neuropsychology of firstepisode schizophrenia: initial characterization and clinical correlates. Am J Psychiatry (2000) 157(4): 549-59. doi:10.1176/appi.ajp.157.4. 549

3. Bora E, Yucel M, Pantelis C. Cognitive impairment in schizophrenia and affective psychoses: implications for DSM-V criteria and beyond. Schizophr Bull (2010) 36(1):36-42. doi:10.1093/ schbul/sbp094

4. Roy MA, Lehoux C, Emond C, Laplante L, Bouchard RH, Everett $\mathrm{J}$, et al. A pilot neuropsychological study of Kraepelinian and nonKraepelinian schizophrenia. Schizophr Res (2003) 62(1-2):155-63. doi: 10.1016/S0920-9964(02)00481-4

5. Palmer BW, Heaton RK, Paulsen JS, Kuck J, Braff D, Harris MJ, et al. Is it possible to be schizophrenic yet neuropsychologically normal? Neuropsychology (1997) 11(3): 437-46. doi:10.1037/0894-4105.11. 3.437

6. Ayesa-Arriola R, Perez-Iglesias R, Rodriguez-Sanchez JM, PardoGarcia G, Tabares-Seisdedos

early stages of the illness. However, there were significant time by group interactions for the parietal tissue volume and the total gray matter volume during the 3-year follow-up period, which might indicate that cognitive deficit in schizophrenia would be associated with progressive brain volume loss. Further investigations are warranted to fully clarify the relationship between cognitive deficit and brain structure in schizophrenia.

\section{ACKNOWLEDGMENTS}

The present study was carried out at the Hospital Marqués de Valdecilla, University of Cantabria, Santander, Spain, under the following grant support: Instituto de Salud Carlos III PI020499, PI050427, PI060507, PI1000183, SENY Fundació Research Grant CI 2005-0308007, and Fundación Marqués de Valdecilla API07/011. We wish to thank the PAFIP researchers. Adele Ferro was sustained by the funds of the 2007/2013 European Social Fund Operational Programme of the Autonomous Region Friuli Venezia Giulia. In addition, we should like to acknowledge the participants and their families for enrolling in this study.

(2003) 60(6):585-94. doi:10.1001/ archpsyc.60.6.585

12. Andreasen NC, Nopoulos P, Magnotta V, Pierson R, Ziebell $\mathrm{S}$, Ho BC. Progressive brain change in schizophrenia: a prospective longitudinal study of first-episode schizophrenia. Biol Psychiatry (2011) 70(7):672-9. doi:10.1016/j.biopsych.2011.05.017

13. Roiz-Santiáñez R, Ayesa-Arriola R, Tordesillas-Gutiérrez D, OrtizGarcía de la Foz V, Pérez-Iglesias R, Pazos A, et al. Three-year longitudinal population-based volumetric MRI study in first-episode schizophreniaspectrum patients. Psychol Med. Available on CJO (2013). doi:10.1017/S0033291713002365

14. DeLisi LE, Hoff AL. Failure to find progressive temporal lobe volume decreases 10 years subsequent to a first episode of schizophrenia. Psychiatry Res (2005) 138(3):265-8. doi:10.1016/j.pscychresns.2005.02. 005

15. Dickey CC, Salisbury DF, Nagy AI, Hirayasu Y, Lee CU, McCarley RW, et al. Follow-up MRI study of prefrontal volumes in firstepisode psychotic patients. Schizophr Res (2004) 71(2-3):349-51. doi: 10.1016/j.schres.2004.04.010

16. Zipursky RB, Christensen BK, Mikulis DJ. Stable deficits in gray matter volumes following a first episode of schizophrenia. Schizophr Res (2004) 71(2-3):515-6. doi:10. 1016/j.schres.2004.02.028

17. Schaufelberger MS, Lappin JM, Duran FL, Rosa PG, Uchida
RR, Santos LC, et al. Lack of progression of brain abnormalities in first-episode psychosis: a longitudinal magnetic resonance imaging study. Psychol Med (2011) 41(8):1677-89. doi:10.1017/ S0033291710002163

18. Roiz-Santianez R, Perez-Iglesias R, Ortiz-Garcia de la Foz V, Tordesillas-Gutierrez D, Mata I, Gonzalez-Mandly A, et al. One year longitudinal study of the straight gyrus morphometry in first-episode schizophrenia-spectrum patients. Psychiatry Res (2012) 202(1):80-3. doi:10.1016/j.pscychresns.2011.10. 001

19. Perez-Iglesias R, TordesillasGutierrez D, McGuire PK, Barker GJ, Roiz-Santianez R, Mata I, et al. White matter integrity and cognitive impairment in first-episode psychosis. Am J Psychiatry (2010) 167(4):451-8. doi:10.1176/appi.ajp. 2009.09050716

20. Wexler BE, Zhu H, Bell MD, Nicholls SS, Fulbright RK, Gore JC, et al. Neuropsychological near normality and brain structure abnormality in schizophrenia. Am J Psychiatry (2009) 166(2):189-95. doi:10.1176/ appi.ajp.2008.08020258

21. Crespo-Facorro B, Perez-Iglesias $\mathrm{R}$, Ramirez-Bonilla $\mathrm{M}$, MartinezGarcia O, Llorca J, Luis VazquezBarquero J. A practical clinical trial comparing haloperidol, risperidone, and olanzapine for the acute treatment of first-episode nonaffective psychosis. J Clin Psychiatry (2006) 67(10):1511-21. doi: 10.4088/JCP.v67n1004 
22. Pelayo-Teran JM, Perez-Iglesias R, Ramirez-Bonilla M, GonzalezBlanch C, Martinez-Garcia O, Pardo-Garcia G, et al. Epidemiological factors associated with treated incidence of first-episode nonaffective psychosis in Cantabria: insights from the Clinical Programme on Early Phases of Psychosis. Early Interv Psychiatry (2008) 2(3):178-87. doi:10.1111/j. 1751-7893.2008.00074.x

23. First MB, Spitzer RL, Gibbon M, Williams J. Structured Clinical Interview for DSM-IV-TR Axis I Disorders - Non Patient Edition. New York: New York State Psychiatric Institute (2001).

24. Andreasen NC, Flaum M, Arndt S. The Comprehensive Assessment of Symptoms and History (CASH). An instrument for assessing diagnosis and psychopathology. Arch Gen Psychiatry (1992) 49(8):615-23. doi:10.1001/ archpsyc.1992.01820080023004

25. Rodriguez-Sanchez JM, AyesaArriola R, Perez-Iglesias R, Perianez JA, Martinez-Garcia O, Gomez-Ruiz $\mathrm{E}$, et al. Course of cognitive deficits in first episode of non-affective psychosis: a 3-year follow-up study. Schizophr Res (2013) 150(1):121-8. doi:10.1016/j.schres.2013.06.042

26. Overall JE, Gorman DR. The brief psychiatric rating scale. Psychol Rep (1962) 10:799-821. doi:10.2466/ pr0.1962.10.3.799

27. Andreasen NC. The Scale for the Assessment of Negative Symptoms (SANS). Iowa City: University of Iowa (1983).

28. Andreasen NC. The Scale for the Assessment of Positive Symptoms (SAPS). Iowa City: University of Iowa (1984).

29. Grube BS, Bilder RM, Goldman RS. Meta-analysis of symptom factors in schizophrenia. Schizophr Res (1998) 31(2-3):113-20. doi:10. 1016/S0920-9964(98)00011-5

30. Rey A. L'examen Clinique en Psychologie. Paris: Presses Universitaires de France (1964).

31. Osterrieth PA. Contribution a l'étude de la perception et de la memoire (The test of copying a complex figure: a contribution to the study of perception and memory). Arch Psychol (1944) 30:286-350.

32. Reitan RM, Wolfson D. The Halstead-Reitan Neuropsychological Test Battery: Therapy and Clinical Interpretation. Tucson, Ariz: Neuropsychological Press (1985).
33. Wechsler D. Weschsler Adult Intelligence Scale-III. San Antonio: The Psychological Corporation (1997).

34. Lezak MD. Neuropsychological Assessment. New York: O. U. Press (1995).

35. Cegalis J, Bowlin J. VIGIL: Software for the Assessment of Attention. Nashua, NH: Forthought (1991).

36. Reichenberg A, Harvey PD, Bowie CR, Mojtabai R, Rabinowitz J, Heaton RK, et al. Neuropsychological function and dysfunction in schizophrenia and psychotic affective disorders. Schizophr Bull (2009) 35(5):1022-9. doi:10.1093/schbul/ sbn044

37. Keefe RS, Fenton WS. How should DSM-V criteria for schizophrenia include cognitive impairment? Schizophr Bull (2007) 33(4):912-20. doi:10.1093/schbul/sbm046

38. Magnotta VA, Harris G, Andreasen NC, O'Leary DS, Yuh WT, Heckel D. Structural MR image processing using the BRAINS2 toolbox. Comput Med Imaging Graph (2002) 26(4):251-64. doi:10.1016/S08956111(02)00011-3

39. Andreasen NC, Rajarethinam R, Cizadlo T, Arndt S, Swayze VW II, Flashman LA, et al. Automatic atlas-based volume estimation of human brain regions from MR images. J Comput Assist Tomogr (1996) 20(1):98-106. doi:10.1097/ 00004728-199601000-00018

40. Harris G, Andreasen NC, Cizadlo T, Bailey JM, Bockholt HJ, Magnotta VA, et al. Improving tissue classification in MRI: a three-dimensional multispectral discriminant analysis method with automated training class selection. J Comput Assist Tomogr (1999) 23(1):144-54. doi:10.1097/00004728-19990100000030

41. Magnotta VA, Heckel D, Andreasen NC, Cizadlo T, Corson PW, Ehrhardt JC, et al. Measurement of brain structures with artificial neural networks: two- and three-dimensional applications. Radiology (1999) 211(3):781-90.

42. Crespo-Facorro B, Roiz-Santianez R, Pelayo-Teran JM, GonzalezBlanch C, Perez-Iglesias R, Gutierrez A, et al. Caudate nucleus volume and its clinical and cognitive correlations in first episode schizophrenia. Schizophr Res (2007) 91(13):87-96. doi:10.1016/j.schres.2006. 12.015

43. Crespo-Facorro B, Roiz-Santianez R, Pelayo-Teran JM, RodriguezSanchez JM, Perez-Iglesias R,
Gonzalez-Blanch C, et al. Reduced thalamic volume in first-episode non-affective psychosis: correlations with clinical variables, symptomatology and cognitive functioning. Neuroimage (2007) 35(4):1613-23. doi:10.1016/j. neuroimage.2007.01.048

44. Brans RG, van Haren NE, van Baal GC, Staal WG, Schnack HG, Kahn RS, et al. Longitudinal MRI study in schizophrenia patients and their healthy siblings. $\mathrm{Br} J$ Psychiatry (2008) 193(5):422-3. doi:10.1192/ bjp.bp.107.041467

45. Ortiz-Gil J, Pomarol-Clotet E, Salvador R, Canales-Rodriguez EJ Sarro S, Gomar JJ, et al. Neural correlates of cognitive impairment in schizophrenia. $\mathrm{Br} J$ Psychiatry (2011) 199(3):202-10. doi:10.1192/ bjp.bp. 110.083600

46. Olabi B, Ellison-Wright I, McIntosh AM, Wood SJ, Bullmore E, Lawrie SM. Are there progressive brain changes in schizophrenia? A meta-analysis of structural magnetic resonance imaging studies. Biol Psychiatry (2011) 70(1): 88-96. doi:10.1016/j.biopsych. 2011.01.032

47. Van Haren NE, Cahn W, Hulshoff Pol HE, Kahn RS. Confounders of excessive brain volume loss in schizophrenia. Neurosci Biobehav Rev (2012) (in press). doi:10.1016/ j.neubiorev.2012.09.006

48. Lieberman JA, Tollefson GD, Charles C, Zipursky R, Sharma T, Kahn RS, et al. HGDH Study Group. Antipsychotic drug effects on brain morphology in firstepisode psychosis. Arch Gen Psychiatry (2005) 62(4):361-70. doi:10.1001/archpsyc.62.4.361

49. Kasai K, Shenton ME, Salisbury DF, Hirayasu Y, Lee CU, Ciszewski AA, et al. Progressive decrease of left superior temporal gyrus gray matter volume in patients with firstepisode schizophrenia. Am J Psychiatry (2003) 160(1):156-64. doi:10. 1176/appi.ajp.160.1.156

50. Nakamura M, Salisbury DF Hirayasu Y, Bouix S, Pohl KM, Yoshida $T$, et al. Neocortical gray matter volume in first-episode schizophrenia and first-episode affective psychosis: a cross-sectional and longitudinal MRI study. Biol Psychiatry (2007) 62(7): 773-83. doi:10.1016/j.biopsych. 2007.03.030

51. Crespo-Facorro B, Roiz-Santianez R, Perez-Iglesias R, PelayoTeran JM, Rodriguez-Sanchez
JM, Tordesillas-Gutierrez D, et al. Effect of antipsychotic drugs on brain morphometry. A randomized controlled one-year follow-up study of haloperidol, risperidone and olanzapine. Prog Neuropsychopharmacol Biol Psychiatry (2008) 32(8):1936-43. doi:10.1016/j.pnpbp.2008.09.020

Conflict of Interest Statement: The study, designed and directed by Benedicto Crespo-Facorro, conformed to international standards for research ethics and was approved by the local institutional review board. Unrestricted educational and research grants from AstraZeneca, Pfizer, Bristol-Myers Squibb, and Johnson \& Johnson provided support to PAFIP activities. No pharmaceutical industry has participated in the study concept and design, data collection, analysis and interpretation of the results, and drafting the manuscript. Prof. Crespo-Facorro has received unrestricted research funding from AstraZeneca, Pfizer, Bristol-Myers Squibb, and Johnson \& Johnson that was deposited into research accounts at the University of Cantabria. Prof. Crespo-Facorro has received honoraria for his participation as a speaker at educational events from Pfizer, BristolMyers Squibb, and Johnson \& Johnson and consultant fees from Pfizer. The rest of the authors report no additional financial.

Received: 05 September 2013; accepted: 01 October 2013; published online: 17 October 2013.

Citation: Ayesa-Arriola $R, \quad$ RoizSantiáñez $R$, Pérez-Iglesias $R$, Ferro A, Sainz J and Crespo-Facorro B (2013) Neuroanatomical differences between first-episode psychosis patients with and without neurocognitive deficit: a 3-year longitudinal study. Front. Psychiatry 4:134. doi: 10.3389/fpsyt.2013.00134 This article was submitted to Schizophrenia, a section of the journal Frontiers in Psychiatry.

Copyright (๑) 2013 Ayesa-Arriola, RoizSantiáñez, Pérez-Iglesias, Ferro, Sainz and Crespo-Facorro. This is an openaccess article distributed under the terms of the Creative Commons Attribution License (CC BY). The use, distribution or reproduction in other forums is permitted, provided the original author(s) or licensor are credited and that the original publication in this journal is cited, in accordance with accepted academic practice. No use, distribution or reproduction is permitted which does not comply with these terms. 